\title{
Estudos métricos da informação na medicina: uma análise bibliométrica na base Scopus
}

\author{
Metric studies of information in medicine: a bibliometric analysis at \\ Scopus database
}

\section{Estudios métricos de la información en la medicina: un análisis bibliométrico en la base Scopus}

\author{
Juliana Lazzarotto Freitas ${ }^{1, a}$ \\ julilazzarotto@gmail.com | https://orcid.org/0000-0003-2572-9407 \\ Maria Cláudia Cabrini Grácio ${ }^{2, b}$ \\ cabrini.gracio@unesp.br | https://orcid.org/0000-0002-8003-0386
}

Leilah Santiago Bufrem ${ }^{3, c}$

santiagobufrem@gmail.com | https://orcid.org/0000-0002-3620-0632

\footnotetext{
${ }^{1}$ Instituto Nacional da Mata Atlântica, Divisão de Ciências. Santa Teresa, ES, Brasil.

2 Universidade Estadual Paulista, Programa de Pós-Graduação em Ciência da Informação. Marília, SP, Brasil.

3 Universidade Federal de Pernambuco, Programa de Pós-Graduação em Ciência da Informação. Recife, PE, Brasil.

a Doutorado em Ciência da Informação pela Universidade Estadual Paulista.

b Doutorado em Lógica pela Universidade Estadual de Campinas.

' Doutorado em Ciências da Comunicação pela Universidade de São Paulo.
}

\section{RESUMO}

O campo de produção científica das ciências da saúde destaca-se historicamente como precursor do desenvolvimento das primeiras pesquisas que consolidaram o uso de fontes de informação científica no Brasil. Este artigo analisa o interdomínio dos estudos métricos da informação com a medicina. Elege o campo da medicina como representativo das ciências da saúde na base de dados Scopus, visando, assim, reconhecer esse espaço de produção científica a partir de indicadores de produtividade e de colaboração relacionados a autores, periódicos e instituições. Caracteriza o interdomínio em um corpus de 132 artigos da autoria de 28 pesquisadores, em um período de 28 anos. Apresenta os autores, periódicos e instituições mais producentes, bem como as relações de coautoria e de cocitação entre autores e periódicos. Define agrupamentos de autores e de periódicos, identificando os mais representativos do interdomínio analisado. Qualifica os artigos conforme os seus enfoques, segundo os três grupos-alvo da bibliometria, presentes em Glänzel (2003), e identifica as suas temáticas de pesquisa. Conclui que os autores mais representativos apresentam estudos com enfoques nos três grupos-alvo e que o periódico Scientometrics é o que estabelece a articulação das pesquisas constituintes do interdomínio de forma mais consistente.

Palavras-chave: Estudos métricos da informação; Análise da produção científica; Interdomínio; Medicina; Ciência da informação. 


\section{ABSTRACT}

The scientific production in health sciences has historically stood out as a precursor to the development of the first studies that consolidated the use of scientific information sources in Brazil. This article analyzes the interdomain between metric studies of information and medicine. The field of medicine is chosen as representative of health sciences in the Scopus database, thus seeking to recognize this space of scientific production from productivity and collaboration indicators related to authors, journals and institutions. It characterizes the interdomain in a corpus of 132 articles by 28 researchers over a 28 -year period. It presents the most productive authors, journals and institutions, as well as the co-authoring and co-citation relationships between authors and journals. It defines clusters of authors and journals, identifying the most representative of the analyzed interdomain. It qualifies articles according to their focus on three target groups of bibliometry, presented by Glänzel (2003), and identifies their research themes. It concludes that the most representative authors present studies focusing on the three target groups and that Scientometrics journal is the one that establishes the articulation of the studies that make up the interdomain in a more consistent way.

Keywords: Metric studies of information; Scientific production analysis; Interdomain; Medicine; Information science.

\section{RESUMEN}

El campo de la producción científica en ciencias de la salud se ha destacado históricamente como precursor del desarrollo de las primeras investigaciones que consolidaron el uso de fuentes de información científica en Brasil. Este artículo analiza el interdominio de los estudios métricos de la información y de la medicina. Se elige el campo de la medicina como representativo de las ciencias de la salud en la base de datos Scopus, con el objetivo de reconocer este espacio de producción científica a partir de indicadores de producción y de colaboración relacionados con autores, revistas e instituciones. Caracteriza el interdominio en un corpus de 132 artículos de 28 investigadores durante un período de 28 años. Presenta los autores, revistas e instituciones más productivos, así como las relaciones de coautoría, citación y cocitación entre autores y revistas. Define grupos de autores y revistas, identificando los más representativos del interdominio analizado. Califica los artículos según su enfoque de acuerdo con los tres grupos alvo de bibliometría, presentes en Glänzel (2003), e identifica sus temas de investigación. Se concluye que los autores más representativos presentan estudios centrados en los tres grupos destinatarios y que la revista Scientometrics es la que establece la articulación de las investigaciones que componen el interdominio de manera más consistente.

Palabras clave: Estudios métricos de la información; Análisis de la producción científica; Interdominio; Medicina; Ciencias de la información.

Este artigo compõe o dossiê Estudos métricos da informação científica em saúde, parte 1.

Contribuição dos autores:

Concepção e desenho do estudo: Juliana Lazzarotto Freitas.

Aquisição, análise ou interpretação dos dados: Juliana Lazzarotto Freitas, Maria Cláudia Cabrini Grácio, Leilah Santiago Bufrem. Redação do manuscrito: Juliana Lazzarotto Freitas.

Revisão crítica do conteúdo intelectual: Maria Cláudia Cabrini Grácio, Leilah Santiago Bufrem.

Declaração de conflito de interesses: não há.

Fontes de financiamento: Fundação de Amparo à Pesquisa do Estado de São Paulo (Fapesp).

Considerações éticas: não há.

Agradecimentos/Contribuições adicionais: não há.

Histórico do artigo: submetido: 10 dez. 2020 | aceito: 16 ago. 2021 | publicado: 10 nov. 2021.

Apresentação anterior: Este trabalho é resultante de desdobramento de parte dos resultados da tese de doutorado da primeira autora. Disponível em: https://repositorio.unesp.br/handle/11449/150189.

Licença CC BY-NC atribuição não comercial. Com essa licença é permitido acessar, baixar (download), copiar, imprimir, compartilhar, reutilizar e distribuir os artigos, desde que para uso não comercial e com a citação da fonte, conferindo os devidos créditos de autoria e menção à Reciis. Nesses casos, nenhuma permissão é necessária por parte dos autores ou dos editores. 


\section{INTRODUÇÃO E PRESSUPOSTOS TEÓRICOS}

Os interdomínios presentes na produção científica como espaços relacionais de pesquisa revelam aproximações entre diferentes domínios ou campos (BUFREM; FREITAS, 2015). A concepção de interdomínio aqui utilizada é uma possibilidade analítica que busca transcender a ideia de interdisciplinaridade, visto que os interdomínios não precisam se consolidar como disciplinas ou campos e não necessariamente demandam a contribuição mútua entre eles. Por essa razão, os interdomínios se constituem em espaços relacionais que permitem a visualização das contribuições de um campo a outro (FREITAS; BUFREM; GRÁCIO, 2019).

Conforme observado por Araújo (2014, p. 119) os estudos mais rigorosos sobre a noção de interdisciplinaridade tratam da necessária existência de um processo teórico e conceitual de mão dupla entre as disciplinas envolvidas. Logo, teóricos constataram a inexistência de práticas interdisciplinares entre a ciência da informação e as demais ciências, sendo que apenas a Ciência da Informação adotava conceitos e metodologias de outros campos sem se fazer notar por eles (ARAÚJO, 2014, p. 119).

A noção de interdomínio como forma de constituição de análises relacionais entre domínios fundamentase na concepção de domínio de Hjørland e Albrechtsen (1995) e Hjørland (2017). Para os autores, um domínio é um núcleo de conhecimento, definido social e teoricamente por um grupo de agentes que partilham compromissos de ordem ontológica e epistemológica. Nesse sentido, o domínio está associado à noção de comunidade discursiva ou de pensamento, cujos integrantes partilham entre si linguagem, estrutura de trabalho, padrões de cooperação, formas de comunicação e organização do conhecimento, sistemas de informação e critérios de relevância (FREITAS; BUFREM; GRÁCIO, 2019). O historiador Christopher Lloyd concebe 'domínio' de ponto de vista similar, como um conjunto de arcabouços teóricos e metodológicos que constituem objetos de investigação (LLOYD, 1995). Lloyd argumenta que a interação social, em tempos e locais bem definidos e dentro de limites impostos por recortes, produz relações e fatos sociais, que, por sua vez, se localizam no tempo e no espaço, e cuja existência e distribuição condicionam a interação social subsequente (LLOYD, 1995).

Ainda como fundamento à concepção de interdomínio, recorre-se ao conceito de disciplinaridade cruzada de Dahlberg (1994), entendido como um trabalho conjunto entre especialistas de diferentes domínios a fim de conhecer, definir e relacionar os conceitos de um domínio, contribuindo para a interação dos domínios e para que seus conceitos interajam (DAHLBERG, 1994).

Posto isso, um interdomínio de pesquisa seria, então, definido como uma imbricação de domínios distintos, podendo, assim, constituir domínios provisórios, fundamentados nas relações de conhecimentos especializados que o enriquecem, permitindo-lhe apresentar, ou não, as características do campo que o originou (FREITAS; BUFREM; GRÁCIO, 2019). O estudo de interdomínios permite identificar relações contributivas e diálogos entre domínios.

Partindo da premissa de que, historicamente, os pesquisadores das ciências da saúde e das ciências biológicas destacam-se como atuantes no campo dos estudos métricos da informação (EMI) em seus respectivos domínios (GRÁCIO; OLIVEIRA, 2012; MATTOS; JOB, 2008), este artigo objetiva caracterizar o interdomínio dos estudos métricos da informação na medicina no Brasil.

Elegendo a área da medicina como representativa das ciências da saúde e assumindo o espaço da produção científica como a materialização de um interdomínio, este estudo se assenta na importância de se reconhecer a representatividade do campo das ciências da saúde para o desenvolvimento dos EMI no Brasil.

Entre os exemplos das contribuições da medicina ao desenvolvimento das primeiras pesquisas que consolidaram o uso de fontes de informação científica no Brasil, destaca-se a iniciativa de criação da base de dados Scientific Electronic Library Online (SciELO) com o intuito de proporcionar mais visibilidade e 
acessibilidade à produção científica nacional, fruto de parceria entre a Fundação de Amparo à Pesquisa do Estado de São Paulo (Fapesp) e o Centro Latino-Americano e do Caribe de Informação em Ciências da Saúde (Bireme). Segundo Packer et al. (1998), um dos principais interesses do Bireme na SciELO foi o desenvolvimento de uma metodologia para publicação eletrônica, cuja aplicação pudesse complementar a metodologia de registro bibliográfico e de indexação utilizada na produção descentralizada da base de dados bibliográficos da Literatura Latino-Americana e do Caribe em Ciências da Saúde (Lilacs). Vale ressaltar esse avanço, dado o sucesso da política de publicação da SciELO, valendo-se da internet para fornecer acesso aberto aos periódicos e facilitar a navegação e a pesquisa em conteúdo de coleções, periódicos, fascículos e artigos (PACKER et. al., 2014).

A relação das ciências da saúde com a Ciência da Informação, a partir dos EMI, também se consolida a partir da criação do Congresso Regional de Informação em Ciências da Saúde (Crics), que vem sendo realizado desde 1992 no Brasil, e do Seminário Internacional de Informação para a Saúde (SINFORGEDS), desde 2010. É importante mencionar, também, como indício da concretização desse interdomínio no campo da CI, que em 2010 ocorreu a criação do Grupo de Trabalho em Informação \& Saúde (GT 11) no Encontro Nacional de Pesquisa em Ciência da Informação (Enancib), principal evento de pesquisa em Ciência da Informação no Brasil.

A Revista Cubana de Información en Ciencias de la Salud, fundada em 1993 e que até o ano de 2012 levou o nome de Acimed, representa outro meio de disseminação da informação nesse interdomínio. O referido periódico tem como objeto de estudo a Ciência da Informação e as suas relações com a saúde. Segundo sua política e seu escopo, constitui-se como uma revista de referência no campo da Ciência da Informação, apresentando suas relações com a saúde a partir de uma perspectiva interdisciplinar (REVISTA CUBANA DE INFORMACIÓN EN CIENCIAS DE LA SALUD, [2016]).

A relação entre os EMI e a medicina também tem sido evidenciada internacionalmente por pesquisadores como J.M. López Piñero e M.L. Terrada Ferrandis, cujas investigações bibliométricas no campo da medicina na Espanha são reconhecidas. Essa relação é corroborada com a criação do Instituto de Historia de la Medicina, em 1985, na Universitat de València por J.M. López Piñero, catedrático de Historia da Medicina da referida universidade. O Instituto dedica-se à pesquisa sobre a história da medicina e da ciência. Atualmente foi reestruturado, adotando a denominação "Institut Interuniversitari López Piñero" de modo a integrar a "Biblioteca histórico-médica Vicente Peset Llorca" e novo "Museo de Historia da Medicina e da Ciência”.

Nas ciências da saúde como um todo, os EMI transcendem sua existência como um conjunto de métodos aplicados que, embora importante, vem sendo complementado por dimensões teórico-práticas integradoras do corpo de conhecimento, para a definição de processos e desenvolvimento de produtos e serviços que permitem a produção e a incorporação do conhecimento às estruturas vigentes.

Assim, o interdomínio de EMI na medicina contribui para a evolução dos campos científicos, da política científica e, especialmente, para a evolução do campo de EMI no Brasil. Isso porque as possibilidades analíticas, a partir dos dados resultantes dos procedimentos quantitativos, representam significativa dimensão para o enfrentamento dos desafios decorrentes do crescimento das publicações e da necessidade de conhecimento da ciência.

Entre outros trabalhos já realizados com o objetivo de relacionar os estudos métricos e a medicina, especialmente devido às relações verificadas nas fronteiras interdominiais, o olhar integrador desta pesquisa visa reconhecer esse espaço de produção científica, a partir de indicadores de produtividade, de colaboração e de citação, procurando identificar as ligações entre autores, periódicos e instituições representativos desse interdomínio de conhecimento. 
Destacam-se, por fim, como pressuposto teórico e metodológico para esta pesquisa, os três grupos-alvo da bibliometria postulados por Glänzel (2003). Para o autor, o G1 refere-se aos estudos de bibliometria para praticantes da bibliometria; o G2 refere-se à bibliometria aplicada às disciplinas científicas; e o G3 seria a bibliometria para a geração de indicadores voltados à política científica e de gestão. Segundo Glänzel (2003), o G1 abarca estudos sobre o domínio da pesquisa bibliométrica de base e preocupa-se em desenvolver a bibliometria de modo teórico e metodológico; o G2 é o domínio de estudos métricos aplicados e constitui o mais abrangente e diversificado grupo da bibliometria, no qual os interesses estão relacionados à área de especialidade trabalhada. Já o G3 é o domínio que orienta políticas científicas e representa o grupo-alvo que é considerado por Glänzel o mais importante da bibliometria contemporânea, também abarcando as pesquisas de avaliação (GLÄNZEL, 2003, p. 9-10). A utilização desses grupos facilita a organização dos estudos bibliométricos, conforme seus usos e suas finalidades e, ainda, se combinados, em vez de serem usados como categorias mutuamente excludentes, podem facilitar a compreensão sobre as características da produção de conhecimento em EMI em distintos interdomínios científicos. Apesar das transformações decorridas no campo científico ao longo dos anos, esses grupos-alvo da bibliometria têm contribuído significativamente para as análises de domínio em EMI.

O artigo articula-se em duas seções, além da introdução que já contempla os pressupostos teóricos do estudo: a metodologia, apresentada em texto descritivo dos procedimentos metodológicos necessários para atingir os objetivos do estudo; e a análise bibliométrica, subdividida em duas subseções, a primeira sobre as 'relações entre periódicos citantes, citados e cocitados', e a segunda, cujo foco são as 'relações entre autores, enfoques e temáticas'. A quarta e última seção refere-se às considerações finais do estudo.

\section{METODOLOGIA}

O interdomínio foi delimitado por meio da identificação dos autores legitimados em artigos científicos sobre estudos métricos da informação, devido à expressiva produtividade desses autores para o campo de EMI no Brasil. A seleção de autores se baseou nos artigos de Mattos e Job (2008), Grácio e Oliveira (2012) e Freitas, Bufrem e Grácio (2019), totalizando 28 autores. Para a seleção do conjunto de artigos de autoria desses pesquisadores, foram localizados na base Scopus os artigos de cada um deles que tratavam de EMI e estavam indexados em periódicos de ciência da informação e de medicina na base Scopus. O conjunto de artigos totalizou 132 textos, abarcando o período de 28 anos (1986-2014).

Exportaram-se os artigos da Scopus, criando-se uma base de dados no software EndNote com os 132 artigos, a fim de contextualizar o corpo da atividade de pesquisa no interdomínio em foco e facilitar a percepção das relações entre autores citantes e citados, periódicos citantes, citados e cocitados, assim como para diferenciar os periódicos nacionais e internacionais.

Os resumos foram lidos para a confirmação da adequação ao recorte. Os campos autor, fonte e instituição de origem dos autores foram organizados em planilha do software Microsoft Excel. Posteriormente, foram criadas as matrizes de relação entre autores citantes e citados, periódicos citantes, citados e cocitados, diferenciando-se periódicos nacionais e internacionais. Foram também identificadas as áreas de pesquisa de cada pesquisador.

O software Ucinet foi utilizado para a criação das redes de coautoria, citação e cocitação e o software SPSS foi usado para a criação dos agrupamentos de autores e periódicos. A caracterização dos enfoques dos artigos foi pautada nos grupos-alvo da bibliometria presentes em Glänzel (2003): G1 - estudos de bibliometria para praticantes da bibliometria; G2 - bibliometria aplicada às disciplinas científicas; G3 - bibliometria para a geração de indicadores voltados à política científica e de gestão. Os grupos foram apresentados como pressupostos teóricos deste estudo na seção introdutória. Por 
fim, as temáticas dos artigos, conforme seus objetos de estudo, foram relacionadas com os autores e com os grupos-alvo de Glänzel.

Identificaram-se 58 periódicos responsáveis pela publicação dos artigos analisados. Desses, 39 (67\%) publicaram apenas um artigo do corpus, sendo considerados transeuntes, ou seja, transitórios, não constituindo um núcleo publicador consolidado na temática e, também, revelando um interdomínio ainda incipiente, ou seja, principiante. No conjunto de referências dos artigos analisados, encontraram-se 735 periódicos distintos citados.

Após a padronização de nomes dos autores responsáveis pelos 132 artigos analisados, totalizaram-se 269 autores distintos, dos quais 26 foram considerados os mais producentes, com pelo menos quatro artigos publicados no domínio.

\section{ANÁLISE BIBLIOMÉTRICA}

Procedemos, nesta seção, alternando entre a apresentação dos resultados evidenciados pelos indicadores e as análises das relações, passíveis de interpretação. Expressa-se, desse modo, o nexo concebido e conceituado pelo estudo, para expressá-lo nas formas de representações. Assim, pode-se descrever a dinâmica da ciência por meio da análise da literatura científica, identificando temáticas próprias ou oriundas de relações interdominiais, autores e instituições que situam e orientam, pelo menos em teoria, as trajetórias e o delineamento de novas questões. Desse modo, ampliam-se as possibilidades de diálogo entre domínios. A configuração da produção periódica científica do interdomínio é aqui retratada por três perspectivas: periódicos, autores e instituições.

\section{Relações entre periódicos citantes, citados e cocitados}

Foram estabelecidas relações entre os periódicos citantes e aqueles referenciados pelos artigos, denominados periódicos citados. A distribuição dos periódicos citantes e citados, e a relação entre citantes e citados e entre os periódicos cocitados num mesmo artigo, é evidenciada na sequência.

A Tabela 1 apresenta os oito periódicos que concentraram a maioria dos artigos analisados (52\%). Observa-se a revista Scientometrics como a mais incidente, com $25 \%$ do corpus analisado, periódico internacional que reflete a institucionalização social dos estudos métricos e se caracteriza como um fórum de articulação de diferentes domínios, visto que pesquisadores de diferentes áreas ali publicam sobre diferentes temáticas.

\section{Tabela 1 - Periódicos citantes mais incidentes no corpus}

\begin{tabular}{llcccc}
\hline Periódicos & País & $\begin{array}{c}\text { No de artigos } \\
\text { que publicou }\end{array}$ & fr (\%) & fa (\%) \\
\hline 1 & Scientometrics & Holanda & 33 & 25 & 25 \\
2 & Braz J Med Biol Res & Brasil & 9 & 7 & 32 \\
3 & Rev Bras Psiquiatria & Brasil & 7 & 5 & 37 \\
4 & Perspect CInf & Brasil & 5 & 4 & 41 \\
5 & Rev Saúde Pública & Brasil & 5 & 4 & 45 \\
6 & Rev Assoc Med Bras & Brasil & 4 & 3 & 48 \\
7 & Cad Saúde Pública & Brasil & 3 & 2 & 50 \\
8 & J Pediatr & Brasil & 3 & 2 & 52 \\
\hline
\end{tabular}

Legenda: Fr (frequência relativa), Fa (frequência acumulada). Fonte: elaboração das autoras. 
Com exceção da Scientometrics, as outras sete revistas mais incidentes são brasileiras. Esse resultado pode ser explicado pelos critérios de seleção do corpus, delimitado por autores brasileiros, que consequentemente publicam mais em revistas nacionais. Destaca-se, ainda, que seis desses periódicos são da área da medicina e um, da área de Ciência da Informação, a saber: revista Perspectivas em Ciência da Informação (Perspect CInf). Assim, considerando-se que o núcleo disseminador do interdomínio analisado está centrado na medicina, observa-se que constitui um corpo de conhecimento metateórico, em que os EMI atuam como método para a compreensão do comportamento, da evolução da medicina e de domínios afins contemplados no escopo dos periódicos.

A Tabela 2 apresenta o conjunto dos 25 periódicos mais referenciados, em que se observa que a Scientometrics, além de ser a publicadora do maior número de artigos do corpus, é também a mais referenciada, ao ser citada na maioria dos artigos analisados (59\%), com um total de 355 (11\% do total) de citações.

\section{Tabela 2 - Periódicos mais citados no corpus}

\begin{tabular}{lcccc} 
Periódicos & País & $\begin{array}{c}\text { Número de } \\
\text { artigos em que é } \\
\text { citado }\end{array}$ & $\begin{array}{c}\text { fr } \\
(\%)^{\mathbf{1}}\end{array}$ & $\begin{array}{c}\text { Número total de } \\
\text { citações } \\
\text { recebidas }\end{array}$ \\
\hline Scientometrics & Holanda & 78 & 59 & 355 \\
Science & EUA & 32 & 24 & 51 \\
Braz J Med Biol Res & Brasil & 31 & 23 & 53 \\
Nature & Reino Unido & 30 & 23 & 46 \\
Rev Saúde Pública & Brasil & 23 & 17 & 45 \\
Cad Saúde Pública & Brasil & 19 & 14 & 36 \\
Research Policy & Holanda & 19 & 14 & 38 \\
The Lancet & Reino Unido & 18 & 14 & 34 \\
JASIST & EUA & 17 & 13 & 32 \\
Ci Inf & Brasil & 15 & 11 & 37 \\
Proc Natl Acad Sci USA & EUA & 15 & 11 & 21 \\
Rev Bras Psiquiatria & Brasil & 15 & 11 & 18 \\
BMJ & Reino Unido & 14 & 11 & 25 \\
JAMA & EUA & 14 & 11 & 22 \\
Rev Assoc Med Bras & Brasil & 14 & 11 & 22 \\
Res Evaluation & Reino Unido & 13 & 10 & 17 \\
Acta Psychiatr Scand & Reino Unido & 11 & 8 & 28 \\
Interciencia & Venezuela & 11 & 8 & 23 \\
Quim Nova & Brasil & 11 & 8 & 19 \\
Social Studies of Science & Reino Unido & 11 & 8 & 11 \\
Am J Psychiatry & EUA & 10 & 8 & 19 \\
Inf Process Manag & Reino Unido & 10 & 8 & 17 \\
J Doc & Reino Unido & 10 & 8 & 16 \\
Arch Gen Psychiatry & EUA & 9 & 7 & 14 \\
Ciênc Saúde Coletiva & Brasil & 9 & 7 & 12 \\
\hline & & & & \\
\hline & & 9 & 17 \\
\hline
\end{tabular}

Legenda: fr (\%)1 - frequência relativa (em \%) calculada em relação ao total de artigos do corpus (132).

Fonte: elaboração das autoras. 
Constata-se que os autores do interdomínio no Brasil citam periódicos brasileiros e internacionais, sendo expressiva a presença de citação a periódicos brasileiros, uma vez que oito (32\%) dos 25 periódicos mais citados são brasileiros.

A revista norte-americana Science, meio de divulgação científica da American Association for the Advancement of Science, é o segundo periódico mais citado nos artigos analisados. A revista Braz J Med Biol Res (23\%), além de ser o segundo periódico com maior disseminação do interdomínio analisado, constitui o terceiro periódico mais citado. Destaca-se que apenas um periódico brasileiro da CI consta entre os mais referenciados, a saber: Ciência da Informação (Ci Inf), a revista mais antiga da área no Brasil.

Entre as revistas mais citadas, observam-se periódicos internacionais de reconhecida excelência no campo da CI. São eles: Journal of the Association for Information Science and Technology (JASIST); Journal of Documentation ( $\mathrm{J}$ Doc) e Information Processing \& Management (Inf Process Manag), sendo o primeiro dos Estados Unidos e os dois últimos do Reino Unido.

Os periódicos mais citados estão agrupados a seguir, via Análise de Cluster (Método Ward e distâncias por Qui-quadrado), em quatro grupos, em função das proximidades em relação ao total de citações recebidas e da frequência de citação nos periódicos citantes mais incidentes assim como nos demais periódicos.

Sobre os quatro grupos estabelecidos, observa-se que o primeiro (G1) é constituído por revistas das ciências sociais aplicadas, exceto pela British Medical Journal (BMJ). Esse grupo não constitui o núcleo de revistas mais incidentes, mas apresenta revistas bastante citadas na Scientometrics e em outras revistas citantes. O G1 também contém as revistas de divulgação científica e apresenta baixa expressividade ou ausência de citações nas revistas da medicina.

O segundo grupo (G2) é composto equitativamente por revistas da CI e de subáreas das ciências exatas e biológicas. É um grupo de revistas bastante citadas na Scientometrics, na Perspectivas em Ciência da Informação e também nas outras revistas citantes. Assim como o G1, esse grupo tem baixo número de citações nas revistas de medicina.

O terceiro grupo (G3) é o menor, constituindo-se somente por revistas da medicina, citadas tanto nas revistas de CI e de ciências sociais como nas de medicina, mas principalmente em outras revistas que constituem o conjunto de revistas citantes do corpus de análise.

O último grupo ( $\mathrm{G}_{4}$ ) contém somente revistas da medicina e é bastante citado por uma revista de psiquiatria e por outras citantes. Também tem quase ausência de citações pelas revistas da CI. 
Tabela 3 - Distribuição da frequência de citação nos periódicos mais citados, segundo agrupamentos $G_{1}, G_{2}, G_{3}$ e $G_{4}$, pelos periódicos citantes mais incidentes no corpus

\begin{tabular}{|c|c|c|c|c|c|c|c|c|c|c|c|}
\hline Grupo & Periódico citado & 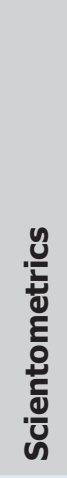 & 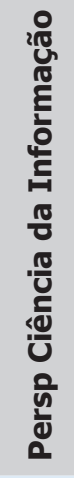 & 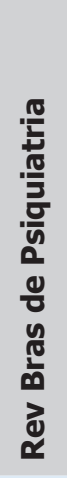 & 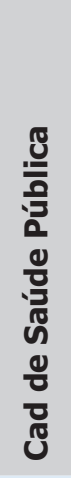 & 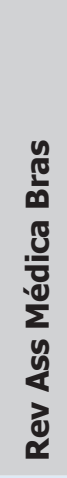 & 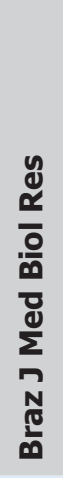 & 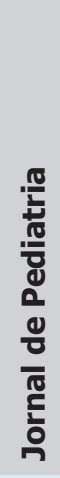 & 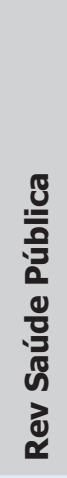 & 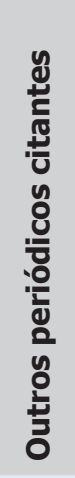 & $\begin{array}{l}\overline{\mathbb{J}} \\
\text { 음 }\end{array}$ \\
\hline \multirow{8}{*}{ G1 } & Science & 16 & 1 & - & - & - & 1 & - & - & 14 & 32 \\
\hline & Res. Policy & 9 & 1 & - & - & - & - & - & - & 9 & 19 \\
\hline & JASIST & 9 & 2 & - & - & - & - & - & - & 6 & 17 \\
\hline & Res Eval & 9 & 1 & - & - & - & - & - & - & 3 & 13 \\
\hline & $\mathrm{BMJ}$ & 4 & - & - & - & - & 2 & - & - & 8 & 14 \\
\hline & Social Studies of Science & 3 & - & - & - & - & - & - & - & 8 & 11 \\
\hline & Scientometrics & 32 & 4 & 2 & 1 & - & 6 & 3 & 3 & 27 & 78 \\
\hline & Nature & 16 & - & - & - & - & 4 & 3 & - & 7 & 30 \\
\hline \multirow{7}{*}{ G2 } & $\mathrm{Ci} \operatorname{Inf}$ & 4 & 3 & - & - & 1 & - & - & - & 7 & 15 \\
\hline & Rev Assoc Med Bras & 2 & 1 & - & - & 3 & 1 & - & - & 7 & 14 \\
\hline & Inf Process Manag & 3 & 1 & - & 1 & - & 1 & 1 & - & 3 & 10 \\
\hline & J Doc & 5 & 2 & - & 1 & - & - & - & - & 2 & 10 \\
\hline & Interciencia & 6 & 1 & - & - & - & 1 & - & - & 3 & 11 \\
\hline & Quim Nova & 4 & 1 & - & - & 1 & 1 & - & - & 4 & 11 \\
\hline & Proc Natl Acad Sci USA & 4 & 2 & - & - & - & 3 & - & 1 & 5 & 15 \\
\hline \multirow{3}{*}{ G3 } & Braz J Med Biol Res & 6 & 1 & 3 & - & - & 2 & 3 & 3 & 13 & 31 \\
\hline & Acta Psychiatr Scand & 1 & - & 2 & - & - & - & 1 & 1 & 6 & 11 \\
\hline & Rev Saúde Pública & 4 & - & 4 & 2 & - & 1 & 1 & 2 & 9 & 23 \\
\hline \multirow{7}{*}{ G4 } & Am J Psychiatry & - & - & 3 & - & - & 1 & - & - & 6 & 10 \\
\hline & Arch Gen Psychiatry & - & - & 3 & - & - & - & - & - & 6 & 9 \\
\hline & Rev Bras Psiquiatria & - & - & 6 & - & 1 & - & 1 & - & 7 & 15 \\
\hline & The Lancet & 1 & - & 5 & 2 & 1 & 1 & - & 1 & 7 & 18 \\
\hline & Ciênc Saúde Coletiva & - & - & 1 & 2 & 1 & 1 & - & - & 4 & 9 \\
\hline & Cad Saúde Pública & 1 & 1 & - & 2 & 2 & 1 & 3 & - & 9 & 19 \\
\hline & JAMA & - & 1 & 1 & - & 1 & 1 & 1 & 1 & 8 & 14 \\
\hline
\end{tabular}

Fonte: elaboração das autoras.

Em síntese, as revistas de CI tendem a não citar as revistas do G4, e as revistas de medicina tendem a não citar as revistas do G1, exceto a Scientometrics, citada por quase todas as revistas citantes da medicina, ainda que em alguns casos com baixa quantidade de citação. Isso sugere uma dispersão desse conhecimento pelos campos, e que fica mais precisa quando da publicação em periódicos do próprio domínio, como é o caso da Scientometrics.

É importante ter em conta que as revistas Science e Nature, entre as mais citadas nesse interdomínio, são periódicos semanais de divulgação científica. Logo, sugere-se a possibilidade de que os EMI tenham 
maior visibilidade em periódicos que contemplam todos os campos científicos, especialmente nos domínios cujas demandas sociais e econômicas são priorizadas devido a sua maior visibilidade social.

Observa-se que as publicações periódicas de medicina, em geral, citam as publicações periódicas de medicina, mas não deixam de citar as publicações de ciências sociais aplicadas, sobretudo a Scientometrics. Por outro lado, as de ciências sociais aplicadas tendem a citar mais revistas da própria área. A relação interdomínios destacada, a partir das revistas citantes e citadas do corpus, permite evidenciar um comportamento de produção compatível com a natureza das áreas cujo interdomínio é estabelecido.

A Figura 1 apresenta as relações de cocitação de periódicos identificados no corpus, permitindo visualizar como se configura, em nível meso, a imagem de um domínio para a comunidade científica.

A Scientometrics é cocitada com todas as outras revistas mais incidentes, comojá observado anteriormente, embora de modo mais intenso com a Braz J Med Biol Res (27), com a Science e a Nature (26).

Já entre os periódicos cocitados da medicina, a maior incidência é entre a Revista de Saúde Pública (Rev Saúde Pública) com a Braz J Med Biol Res (16), ambas brasileiras.

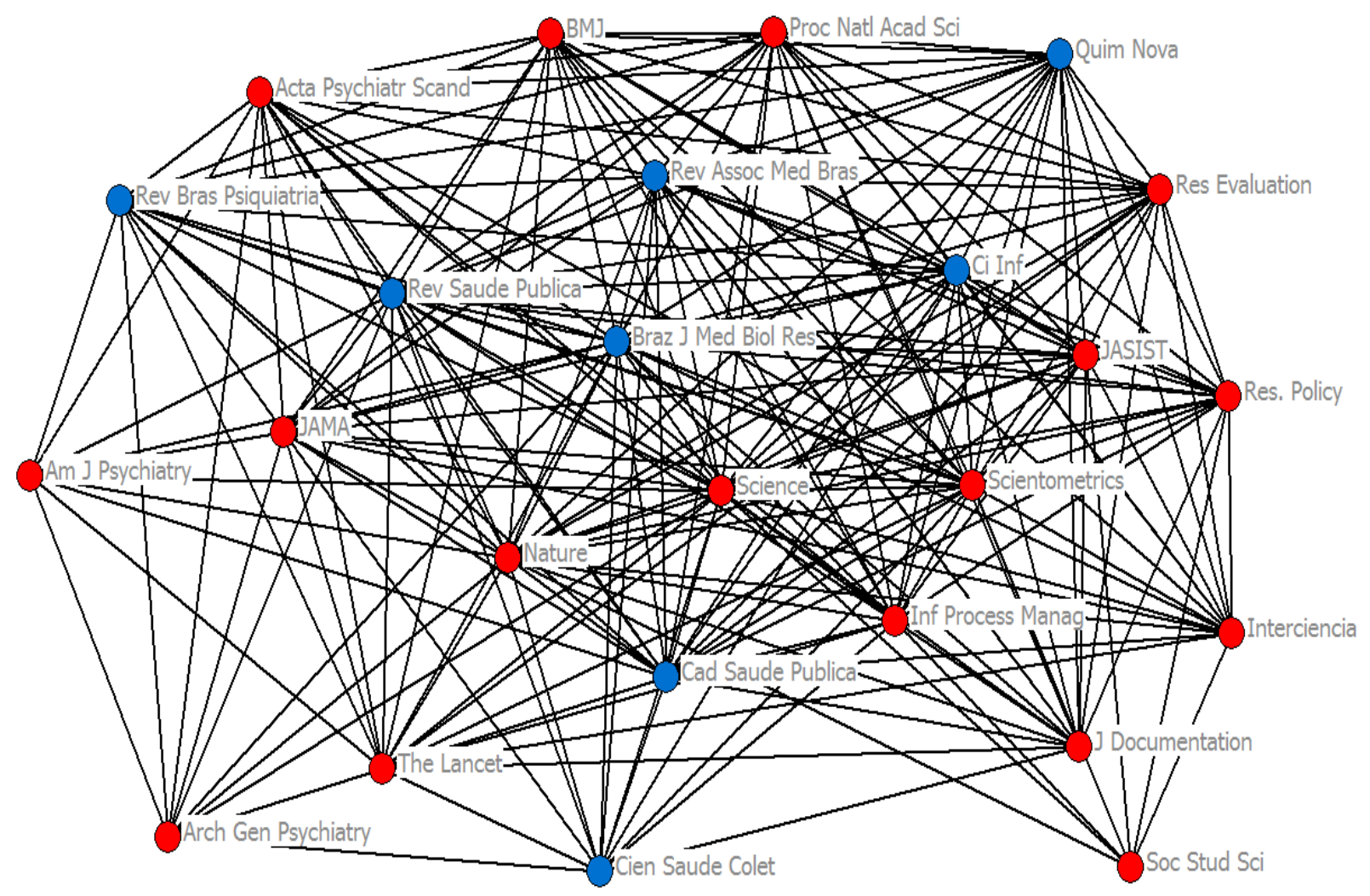

Legenda: vermelho: periódicos internacionais; azul: periódicos nacionais.

Figura 1 - Rede de periódicos cocitados no corpus dos 132 artigos que compõem o interdomínio analisado.

Fonte: elaboração das autoras.

Entre as revistas mais cocitadas das ciências sociais aplicadas, têm-se a Scientometrics com a JASIST (16) e a Ci Inf com a Scientometrics (10). A relação de cocitação que melhor caracteriza o interdomínio estudado é entre a revista Ci Inf e a revista Braz J Med Biol Res (4). Porém, nota-se que essa relação apresenta pouca expressividade numérica. Quando se considera apenas a relação entre as revistas de ciências sociais aplicadas e as de medicina, a relação de cocitação que se destaca é a da Revista da Associação Médica Brasileira (Rev Assoc Med Bras) com a Scientometrics (10), que é mais expressiva que a relação entre a medicina e a Ciência da Informação anteriormente mencionada.

Ainda sobre a rede de cocitação, destaca-se que grande parte das revistas da CI são internacionais e as da medicina são brasileiras, salvo três internacionais da subárea de psiquiatria, que se notabilizam. Evidencia- 
se também que a cocitação de revistas brasileiras e estrangeiras é mais comum na CI, e a cocitação na medicina ocorre entre revistas brasileiras da área.

Em contrapartida, a medicina apresenta maior número de periódicos nacionais indexados na Scopus, assim como em outras bases. Além disso, a política científica dessa área, cujos critérios de visibilidade são prioritariamente os indicadores de impacto, tem incentivado seus periódicos a citarem a literatura brasileira como meio de valorizar a produção científica nacional. Essa preocupação é evidenciada na literatura científica analisada, como nos estudos de Teixeira et al. $(2012,2013,2014)$ sobre a presença de referências e citações a autores brasileiros na produção científica nacional.

\section{Relações entre autores, enfoques e temáticas}

A Tabela 4 apresenta os quatro agrupamentos dos 26 autores mais produtivos (correspondente a ter publicado pelo menos quatro artigos) no corpus de 132 artigos analisados, de acordo com a proximidade com os três grupos-alvo de atuação dos estudos bibliométricos presentes em Glänzel (2003).

Tabela 4-Agrupamento dos autores, segundo a quantidade de artigos publicados, de acordo com os grupos-alvo de Glänzel (2003)

\begin{tabular}{|c|c|c|c|c|c|c|c|c|}
\hline \multirow{12}{*}{ A } & Autores & G1 & G1 e G2 & G1 e G3 & G1, G2 e G3 & $\mathbf{G 2}$ & G2 e G3 & G3 \\
\hline & Lima LS & - & - & - & - & - & 4 & - \\
\hline & Herculano RDA & - & - & - & - & 3 & 1 & - \\
\hline & Razzouk D & - & - & - & - & 1 & 9 & - \\
\hline & Gerolin J & - & - & - & 1 & - & 8 & - \\
\hline & Martelli Junior H & - & - & - & - & 1 & 4 & - \\
\hline & Bressan RA & - & - & - & - & 1 & 4 & - \\
\hline & Mari JJ & - & - & - & 1 & 2 & 13 & - \\
\hline & Colosimo EA & - & 1 & - & - & - & 4 & - \\
\hline & Oliveira EA & - & 1 & - & - & - & 3 & - \\
\hline & Oliveira MCLA & - & 1 & - & - & 1 & 5 & - \\
\hline & Quirino IG & - & 1 & - & - & 1 & 5 & - \\
\hline \multirow{10}{*}{ B } & Martelli DRB & - & 1 & - & - & 1 & 6 & - \\
\hline & Pereira JCR & - & - & 2 & 2 & 2 & 5 & - \\
\hline & Wainer J & - & - & 3 & 1 & 1 & 2 & - \\
\hline & Leta J & - & 3 & 3 & 3 & 4 & 5 & - \\
\hline & Meneghini R & - & - & 4 & 2 & - & 7 & - \\
\hline & de Meis L & 1 & - & - & 2 & - & 3 & - \\
\hline & Velho L & 1 & - & 6 & 1 & 1 & 3 & 5 \\
\hline & Escuder MML & - & - & 2 & - & - & 2 & 2 \\
\hline & Packer AL & - & - & 6 & 1 & 1 & - & - \\
\hline & Figueira IL & - & - & 1 & - & 4 & 3 & - \\
\hline \multirow[t]{2}{*}{ C } & Coutinho ESF & - & - & 1 & - & 3 & 3 & - \\
\hline & Mendlowicz MV & - & - & 1 & - & 6 & 3 & - \\
\hline \multirow{3}{*}{ D } & Botelho NM & - & 2 & 1 & - & 2 & 1 & - \\
\hline & Teixeira RKC & - & 2 & 1 & - & 2 & 1 & - \\
\hline & Gouveia FC & - & 2 & 1 & - & 2 & - & - \\
\hline
\end{tabular}

Legenda: G1: estudos de bibliometria para praticantes da bibliometria; G2: bibliometria aplicada às disciplinas científicas; G3: bibliometria para a geração de indicadores voltados à política científica e de gestão.

Fonte: elaboração das autoras. 
O agrupamento A caracteriza-se pela forte atuação em G2 (bibliometria aplicada às disciplinas científicas) e G3 (bibliometria para a geração de indicadores voltados à política científica e de gestão) simultaneamente. Em contrapartida, nenhum dos autores atua exclusivamente nos grupos que contemplam G1 (estudos de bibliometria para praticantes da bibliometria). Desse modo, é um grupo focado nos estudos metateóricos em que a bibliometria é aplicada para a análise da evolução e do comportamento do conhecimento gerado na medicina, muitas vezes visando a questões de pesquisa relacionadas à gestão e à avaliação de políticas científicas.

Já o agrupamento B apresenta expressiva pesquisa sobre questões abrangidas simultaneamente pelos grupos-alvo G1, G2 e G3. Ainda que de forma menos intensa, esse grupo também é o único que trabalha com questões que se ocupam exclusivamente do desenvolvimento dos EMI, buscando contribuir com o avanço da própria bibliometria, com estudos de bibliometria voltados para pesquisadores do campo da bibliometria (G1) e/ou com estudos voltados para a política científica e de gestão (G3). Assim, apresenta destacada presença na busca por reflexão e desenvolvimento do próprio domínio dos EMI, tomando a medicina como universo de estudo, a fim de colaborar para as tomadas de decisão em política científica. Nota-se que os autores que o representam apresentam diferentes titulações, que, embora sejam predominantemente das ciências biológicas e da saúde, não são prioritariamente da medicina, como nos outros grupos.

O agrupamento $\mathrm{C}$ não se ocupa com questões relativas ao próprio desenvolvimento dos EMI (G1), não contribuindo assim para o avanço e a evolução dos EMI. Porém, apresenta forte atuação nas pesquisas que buscam analisar o domínio da medicina (G2) e, também, em pesquisas que utilizam o conhecimento dos estudos métricos para analisar o domínio da medicina e contribuir para a sua política científica (G2 e G3 simultaneamente). Todos os autores desse agrupamento são médicos.

Já o agrupamento D, prioritariamente de médicos, é o único em que todos têm forte atuação em G1 e G2, mas inexpressiva atuação em G3.

Considera-se que pesquisadores atuantes em G1 e G2, ou, ainda, em G1, G2 e G3, são aqueles cuja expressividade de contribuição define o interdomínio de EMI na medicina. Nesse caso, o interdomínio constitui-se e consolida-se a partir das contribuições dos agrupamentos B e D. Seus autores são provenientes, de modo especial, da Universidade Federal de São Paulo (Unifesp), e suas titulações são prioritariamente em ciências biológicas e saúde. Contudo, há autores das ciências sociais aplicadas e da ciência da computação que se enquadram especificamente no agrupamento B.

Destaca-se que os autores dos grupos B e D apresentam produção expressiva de artigos na qual os EMI são considerados objetos de pesquisa e, também, apresentam referencial teórico relativo aos seus objetos.

A Figura 2 apresenta as temáticas predominantes nos artigos produzidos pelos 26 autores mais produtivos do corpus, conforme seus objetos de estudo. 


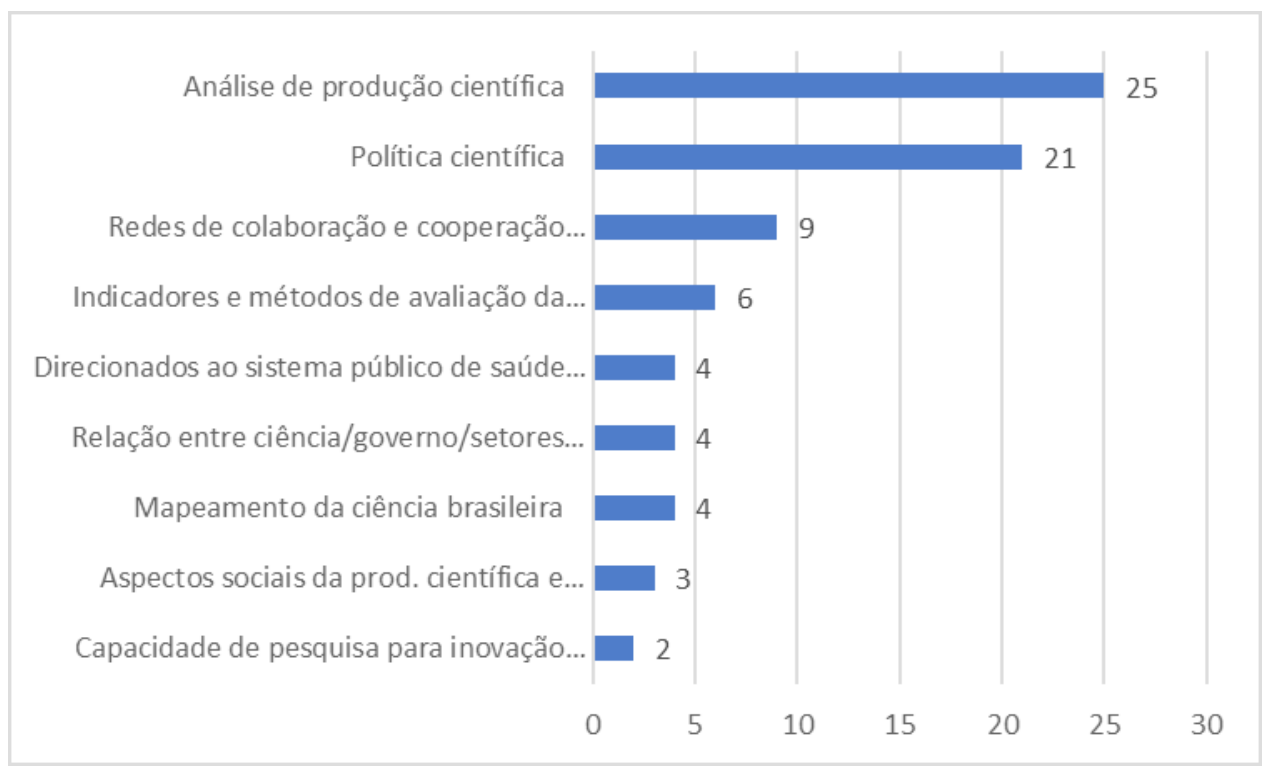

Figura 2 - Temáticas predominantes no corpus dos artigos publicados pelos 26 autores mais produtivos ( $>=2$ incidências)

Fonte: elaboração das autoras.

Observa-se (Figura 2) que os artigos mais frequentes sobre 'Análise de produção científica' analisam a literatura de diferentes especialidades, sendo, em sua maioria, aplicados às disciplinas científicas. Em seguida, encontram-se os que têm como alvo a 'Política científica', remetendo especialmente aos estudos do grupo G3 de Glänzel (2003), que também podem pertencer simultaneamente aos outros grupos-alvo.

Já os estudos que têm como temática as 'Redes de colaboração e cooperação científica' voltam-se à análise das relações entre países, instituições, áreas de pesquisa, programas, autores e inclusive entre grupos de países como os que integram o Mercosul. Os estudos sobre 'Indicadores e métodos de avaliação', embora com menor expressividade numérica, mostram que o desenvolvimento de métodos e de indicadores é uma das questões tratadas no interdomínio.

Deve-se esclarecer que a categoria 'Mapeamento da ciência brasileira', apesar de não eliminar a possibilidade de se voltar às políticas científicas, à colaboração e à cooperação em pesquisa, foi categorizada individualmente porque expressa uma intenção mais abrangente que as temáticas anteriormente mencionadas. Aponta-se a categoria 'Aspectos sociais da produção científica' como objeto de estudo dos autores mais produtivos, porém ela incide com menor expressividade numérica.

A Tabela 5 apresenta as instituições a que são vinculados os autores e as áreas de suas últimas titulações. Nota-se que os autores mais incidentes advêm da Universidade Federal de São Paulo - Unifesp (23\% do universo) e têm formação em medicina, com especialidade na psiquiatria, resultado compatível com a análise de conteúdo da produção periódica científica, que destaca a psiquiatria e a saúde mental como domínio de aplicação mais frequente dos estudos métricos no interdomínio (FREITAS, 2017).

Observa-se que 30\% dos autores que atendem ao critério de pelo menos quatro artigos publicados são bolsistas de produtividade em pesquisa do Conselho Nacional de Desenvolvimento Científico e Tecnológico (CNPq) em diferentes áreas. Dos oito bolsistas, quatro são afiliados às instituições mais produtivas, sendo dois deles da Unifesp. 
Tabela 5 - Instituições de vínculo dos autores com pelo menos quatro artigos publicados no corpus analisado

\begin{tabular}{|c|c|c|c|c|c|}
\hline $\begin{array}{l}\text { Instituições } \\
\text { de vínculo dos } \\
\text { autores }\end{array}$ & $\begin{array}{c}\mathrm{N}^{0} \text { de } \\
\text { pesquisa- } \\
\text { dores }\end{array}$ & $\%$ & $\begin{array}{l}\mathrm{N}^{\circ} \text { de } \\
\text { artigos } \\
\text { publicados }\end{array}$ & $\begin{array}{c}\text { Bolsas } \\
\text { PQ }\end{array}$ & Área da última titulação \\
\hline UNIFESP & 6 & 23 & 52 & 2 & $\begin{array}{l}\text { Psiquiatria (2); Psiquiatria e psicologia médica (2); } \\
\text { Bioquímica (1); Ciência da Informação (1) }\end{array}$ \\
\hline UFRJ & 3 & 11 & 34 & - & $\begin{array}{l}\text { Química biológica (1); Psiquiatria e saúde mental (1); } \\
\text { Medicina (1) }\end{array}$ \\
\hline UNIMONTES & 3 & 11 & 22 & 1 & Ciências da saúde (2); Medicina (1) \\
\hline UFMG & 3 & 11 & 17 & 1 & Estatística (1); Medicina (2) \\
\hline UNICAMP & 2 & 8 & 23 & 2 & $\begin{array}{l}\text { Política científica e tecnológica (1); Ciência da } \\
\text { computação (1) }\end{array}$ \\
\hline UEPA & 2 & 8 & 12 & & Medicina (2) \\
\hline FIOCRUZ & 2 & 8 & 10 & 1 & Saúde pública (1); Química biológica (1) \\
\hline USP & 1 & 4 & 10 & & Medicina (1) \\
\hline UFF & 1 & 4 & 9 & 1 & Psiquiatria e saúde mental (1) \\
\hline UNIFENAS & 1 & 4 & 7 & - & Ciências da saúde (1) \\
\hline $\begin{array}{l}\text { INSTITUTO DE } \\
\text { SAÚDE-SP }\end{array}$ & 1 & 4 & 6 & - & Ciências da saúde (1) \\
\hline UNESP & 1 & 4 & 5 & - & Física aplicada à medicina e à biologia (1) \\
\hline TOTAL & 26 & 100 & & 8 & \\
\hline
\end{tabular}

Fonte: elaboração das autoras.

Em relação às coautorias no corpus, observa-se, na Figura 3, grupos consolidados que trabalham em colaboração. Os pesquisadores desses grupos foram autores de pelo menos quatro artigos no domínio. Os destacados em azul estão isolados na rede de colaboração entre os mais producentes, não porque produzem exclusivamente em autoria individual - exceto Velho, que apresenta artigos em autoria única -, mas porque seus coautores não têm produção maior que três artigos, ficando, assim, fora da rede. 

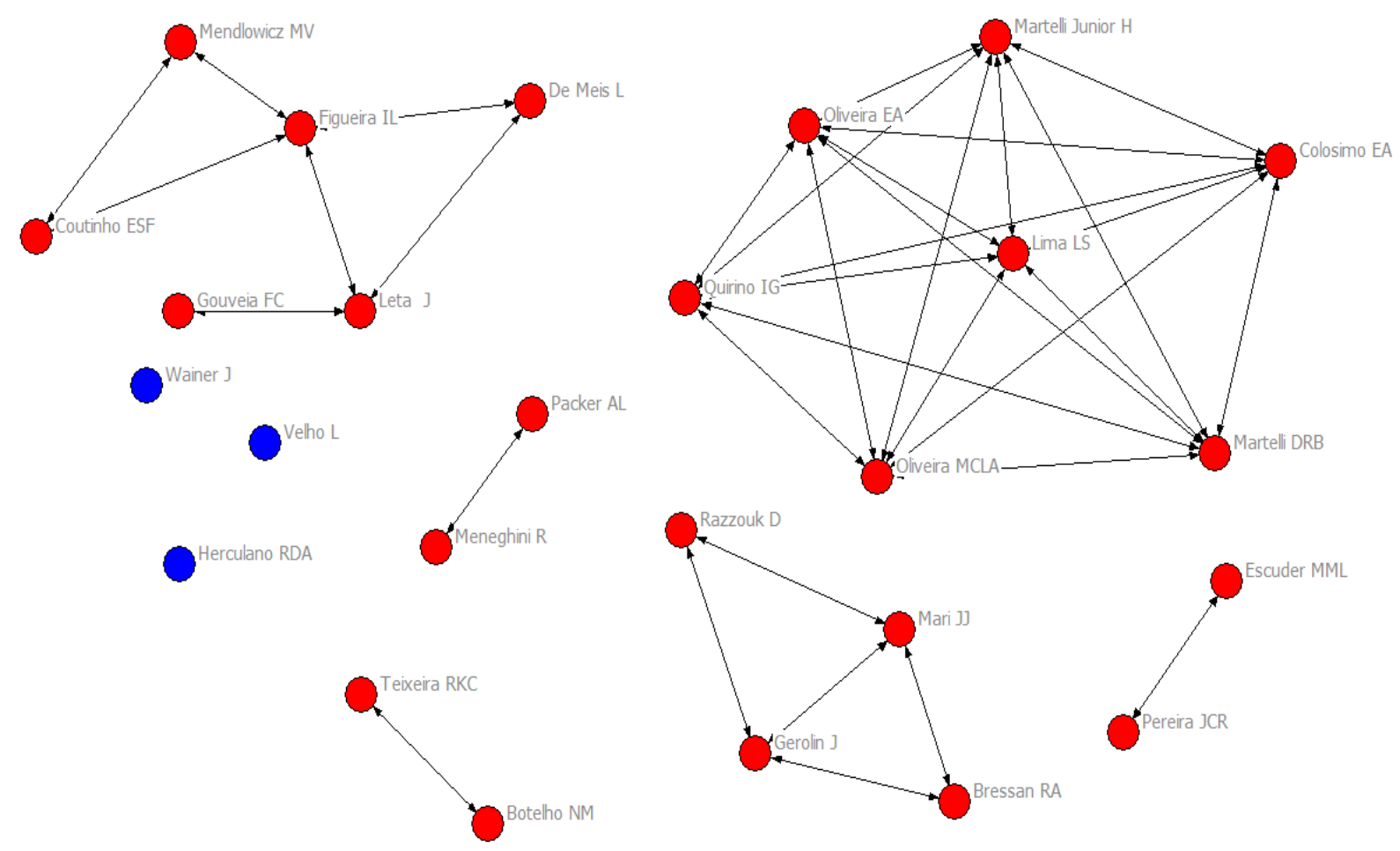

Figura 3 - Rede de coautoria entre os autores do corpus com pelo menos quatro artigos

Fonte: elaboração das autoras.

Observa-se que o maior grupo da rede é composto por sete autores, representando apenas duas instituições de pesquisa, a Universidade Federal de Minas Gerais (UFMG) e a Universidade Estadual de Montes Claros (Unimontes). Nesse grupo, 57\% dos autores são médicos, sendo dois deles formados em odontologia e apenas um nas ciências exatas, com doutorado em estatística, também bolsista de produtividade em pesquisa 2 do CNPq da área de estatística. Esse grupo atuante no interdomínio apresenta integrantes com uma contínua e ativa participação no domínio de EMI.

Ainda sobre a Figura 3, observa-se um segundo grande grupo, composto por seis autores que colaboram entre si. Esse grupo advém das instituições: Universidade Federal do Rio de Janeiro (UFRJ), Fundação Oswaldo Cruz (Fiocruz) e Universidade Federal Fluminense (UFF), no qual 67\% dos autores são médicos e o restante tem formação nas ciências biológicas. Um dos pesquisadores componentes do grupo é bolsista de produtividade em pesquisa 1A do CNPq, na área de saúde coletiva e nutrição.

Já a Universidade Federal de São Paulo (Unifesp) é a instituição da qual procede o terceiro maior grupo de autores colaboradores do interdomínio, formado por quatro autores, ambos com doutorado em psiquiatria e saúde mental, sendo um deles bolsista de produtividade em pesquisa 1A do CNPq na medicina. Embora esse grupo seja menor que o grupo de autores filiados às instituições dos estados do Rio de Janeiro e de Minas Gerais, ele se destaca pela homogeneidade de domínios de atuação e de formação dos pesquisadores.

Além disso, aponta-se uma dupla de pesquisadores também oriundos da Unifesp, mais especificamente da Fundação de Apoio à Universidade Federal de São Paulo (FapUnifesp), Packer e Meneghini, que publicam em coautoria e que não apresentam titulação na medicina.

Esses resultados podem ser um indicativo de que, no Brasil, o interdomínio estudado se estrutura por meio de um grupo coeso e centrado em instituições específicas. Arrisca-se sugerir que o interdomínio pode ser considerado consignado a esses quatro grupos de autores e suas respectivas universidades, podendo-se afirmar, inclusive, que alguns dos autores em destaque seriam pioneiros desse interdomínio no Brasil, visto que são referendados no domínio de estudos métricos consignado à Ciência da Informação. 
Os autores da rede contribuem para o desenvolvimento de estudos relacionados ao G1 de Glänzel, sendo que sete deles contribuem mais intensamente, e os outros, com pouca intensidade.

Outra dupla que se evidencia pela quantidade de artigos publicados é da Universidade do Estado do Pará (UEPA), ambos da medicina e com titulação de doutorado em cirurgia experimental.

Por fim, dois dos autores que aparecem na rede com autoria individual advêm da Universidade Estadual de Campinas (Unicamp), com doutorado em áreas distintas - um na ciência da computação e outro em política científica e tecnológica. O último autor que aparece isolado na rede, em azul, é o único representante da Universidade Estadual Paulista (Unesp), não sendo da medicina, mas com doutorado em temática que relaciona sua área à medicina.

A Tabela 6 apresenta a área da titulação dos pesquisadores da rede de colaboração dos autores mais produtivos no interdomínio de EMI na medicina. Observa-se, de modo geral, que esse interdomínio se constitui predominantemente de médicos (54\%). Além disso, conforme a divisão de áreas do CNPq, a maioria (65\%) deles apresenta graduação nas ciências da saúde, 12\% nas ciências biológicas, 19\% nas ciências exatas e da terra e $4 \%$ nas ciências sociais aplicadas. Entretanto, esses dois últimos estabelecem, em algum momento de sua formação, uma relação interdominial com a saúde, decorrente ou da afinidade temática ou da área de atuação e/ou departamento a que estão afiliados.

Tabela 6 - Titulações da graduação e última titulação dos pesquisadores da rede de coautoria dos autores mais produtivos no interdomínio de EMI na medicina

\begin{tabular}{|c|c|c|c|c|}
\hline $\begin{array}{l}\text { Grandes } \\
\text { áreas }\end{array}$ & $\begin{array}{l}N^{\circ} \text { de } \\
\text { autores }\end{array}$ & $\%$ & $\begin{array}{l}\text { Áreas } \\
\text { de graduação }\end{array}$ & Áreas da última titulação \\
\hline \multirow[t]{2}{*}{$\begin{array}{l}\text { Ciências da } \\
\text { saúde }\end{array}$} & \multirow[t]{2}{*}{17} & \multirow[t]{2}{*}{$65 \%$} & Medicina (14) & $\begin{array}{l}\text { Psiquiatria e saúde mental (2) } \\
\text { Psiquiatria e psicologia médica (2) } \\
\text { Saúde pública (1) } \\
\text { Epidemiologia e estatística (1) } \\
\text { Epidemiologia (1) } \\
\text { Epidemiologia psiquiátrica (1) } \\
\text { Téc. operatórias e cirurgia exper. (1) } \\
\text { Ciências da saúde (2) } \\
\text { Gastroenterologia (1) } \\
\text { Bioquímica (1) } \\
\text { Cirurgia experimental (1) }\end{array}$ \\
\hline & & & $\begin{array}{l}\text { Odontologia (2) } \\
\text { Não identificado (1) }\end{array}$ & $\begin{array}{l}\text { Estomatologia (1) } \\
\text { Ciências da saúde (1) } \\
\text { Epidemiologia } \\
\text { Estatística (1) }\end{array}$ \\
\hline $\begin{array}{l}\text { Ciências } \\
\text { biológicas }\end{array}$ & 3 & $12 \%$ & $\begin{array}{l}\text { Ciências biológicas (2) } \\
\text { Química (1) }\end{array}$ & $\begin{array}{l}\text { Química biológica (2) } \\
\text { Bioquímica (1) }\end{array}$ \\
\hline $\begin{array}{l}\text { Ciências } \\
\text { exatas e da } \\
\text { terra }\end{array}$ & 5 & $19 \%$ & $\begin{array}{l}\text { Física (1) } \\
\text { Eng. elétrica (1) } \\
\text { Eng. eletrônica (1) } \\
\text { Desenvolv. de sistemas (1) } \\
\text { Engenharia agronômica (1) }\end{array}$ & $\begin{array}{l}\text { Física ap. à medicina e biologia (1) } \\
\text { Estatística (1) } \\
\text { Ciência da computação (1) } \\
\text { Psiquiatria e psicologia médica (1) } \\
\text { Política científica e tecnológica (1) }\end{array}$ \\
\hline $\begin{array}{l}\text { Ciências } \\
\text { sociais } \\
\text { aplicadas }\end{array}$ & 1 & $4 \%$ & Bs Management (1) & Ciência da Informação (1) \\
\hline
\end{tabular}

Fonte: elaboração das autoras.

Os aspectos a serem superados para a realização de EMI em ambos os campos, medicina e Ciência da Informação, convergem em suas características de produção e evidenciam a necessidade de trabalho 
conjunto com profissionais da ciência da computação e da estatística. Com efeito, pode-se sugerir um fortalecimento do ensino dessas disciplinas nas grades curriculares da CI, especialmente no que tange aos conhecimentos mais utilizados, oriundos desses domínios para o trabalho com os EMI.

Em relação aos 4.682 autores citados, apenas 10,4\% foram citados três ou mais vezes, o que demonstra uma dispersão teórica característica do interdomínio, já que conjuga temáticas de ambas as áreas.

A Tabela 7 apresenta, em ordem decrescente, os 19 autores que foram citados em pelo menos 13 artigos do corpus, correspondendo a ser citado em pelo menos $10 \%$ da produção científica analisada. Observa-se que 15 (79\%) dos autores mais citados são também aqueles mais produtivos (presentes na Figura 3) e foram destacados em azul. Isso pode sugerir que há uma quantidade expressiva de autocitações usadas como fundamento desses estudos. Todavia, as autocitações, quando ocorreram, justificam-se principalmente porque a comunidade que atua no interdomínio é limitada, já que são poucos os que trabalham com estudos métricos e que subsidiam a aplicação e a construção do conhecimento em EMI na medicina.

\section{Tabela 7-Autores mais citados no corpus de 132 artigos analisados}

\begin{tabular}{|lcc|}
\hline Autores mais citados & $\begin{array}{c}\text { Número de artigos } \\
\text { em que foi citado }\end{array}$ & $\begin{array}{c}\text { Total de citações } \\
\text { recebidas }\end{array}$ \\
\hline Leta J & 37 & 84 \\
Glänzel W & 37 & 67 \\
Meneghini R & 31 & 67 \\
de Meis L & 25 & 50 \\
Mari JJ & 24 & 75 \\
Packer AL & 18 & 41 \\
Bressan RA & 18 & 35 \\
Gerolin J & 17 & 44 \\
\hline Garfield E & 17 & 38 \\
\hline Figueira I & 17 & 28 \\
Guimarães JA & 16 & 16 \\
Velho L & 15 & 48 \\
\hline Razzouk D & 15 & 27 \\
Dubugras MTB & 14 & 25 \\
\hline Hirsch JE & 14 & 15 \\
\hline Saxena S & 13 & 47 \\
Zorzetto R & 13 & 24 \\
\hline Schubert A & 13 & 21 \\
Moed HF & 13 & 16 \\
\hline
\end{tabular}

Legenda: azul: autores que também são responsáveis pela publicação de artigos do corpus.

Fonte: elaboração das autoras.

A maioria dos pesquisadores é constituída por médicos psiquiatras ou afiliados a departamentos de saúde mental. Entre eles, estão R. Bressan, J. Mari, D. Razzouk e I.L.V. Figueira, cuja produção científica relacionada aos estudos métricos da informação ocorre em seus respectivos campos. Do mesmo modo, J. Gerolin, orientado por J. Mari no mestrado em psiquiatria e psicologia médica da Unifesp, apresenta formação de graduação em desenvolvimento de sistemas. Este último atua em pesquisas relacionadas às políticas de avaliação nos programas de pós-graduação de psiquiatria no Brasil e coordena o Setor de Cientometria da Unifesp. 
A.L. Packer é o único pesquisador entre os mais citados que se situa também entre os mais produtivos com titulação em Ciência da Informação, tendo sido diretor do Programa SciELO/Fapesp e ex-diretor da Bireme.

R. Meneghini advém dos campos da química e da bioquímica, é pesquisador do CNPq em bioquímica e atua em estudos relacionados à comunicação científica e à ciência brasileira. Foi cocriador do projeto SciELO e agraciado com a Grã-Cruz da Ordem Nacional do Mérito Científico pelo reconhecimento às contribuições científicas e técnicas para o desenvolvimento da ciência no Brasil.

Assim como Meneghini e Packer, J.A. Guimarães apresenta uma participação intensa na política científica brasileira, tendo ocupado distintos cargos, como diretor do CNPq, presidente da CAPES, entre outros postos de destaque, como na Sociedade Brasileira para o Progresso da Ciência (SBPC), e no Ministério da Ciência e Tecnologia. Atualmente, é docente da Universidade Federal do Rio Grande do Sul (UFRGS).

J. Leta, graduada em ciências biológicas, é docente do Instituto de Bioquímica Médica da Universidade Federal do Rio de Janeiro (UFRJ) e do Programa de Pós-Graduação em Ciência da Informação do convênio UFRJ/IBICT. Há mais de vinte anos, ela conduz pesquisas no campo da bibliometria/cienciometria, com ênfase nas análises da produção científica brasileira. Seu orientador de mestrado e doutorado, L. de Meis (falecido em dezembro de 2014), cientista da bioquímica e professor emérito da mesma instituição, aparece como um dos autores mais produtivos e citados nesta pesquisa.

L. Velho, com graduação em ciências agrárias, é docente de estudos sociais da ciência e da tecnologia na Unicamp. M.T.B. Dubugras é doutora em saúde coletiva pela Unifesp, especialista em divulgação científica e em comunicação em saúde e, também, consultora da Organização Pan-Americana da Saúde. R. Zorzetto tem doutorado em bioinformática e atua como docente da Universidade de São Paulo (USP). Todos apresentam alguma relação com a medicina. Quando as relações não se evidenciam a partir das titulações e/ou afiliações institucionais, são decorrentes de projetos e linhas de pesquisa.

Os autores internacionais mais citados, como J. Hirsch, H. Moed, A. Schubert, E. Garfield e S. Saxena, advêm de campos como a física, a química e a medicina. Além disso, Garfield foi um dos pioneiros dos EMI, tendo criado o Institute for Scientific Information (ISI) e o Science Citation Index (SCI) (1964). Hirsch, por sua vez, notabilizou-se com o índice h, em 2005, indicador para mensurar a consolidação de pesquisadores por meio da análise da produtividade e do impacto de citação que recebem.

Entre esses autores, alguns foram pioneiros no desenvolvimento dos estudos métricos e têm relevância política para a ciência, além de apresentarem formação majoritária nas ciências da saúde e biológicas, e nas exatas.

Para a análise sobre os autores mais citados, é relevante retomar estudo de Bufrem, Freitas e Gabriel Jr. (2014), em que analisam a literatura brasileira de CI sobre EMI sob a dimensão da autoria. Nesse estudo, despontam alguns pesquisadores muito citados no domínio de EMI e que também recebem citações expressivas pelos autores desse interdomínio, a saber: W. Glänzel, L. Velho e E. Garfield. Bufrem, Freitas e Gabriel Jr. (2014) apontam que esses pesquisadores estão entre aqueles que estabelecem o diálogo das pesquisas empíricas e teóricas relativas aos EMI.

A Figura 4 apresenta a rede de cocitação entre os autores mais citados, em que se observam algumas relações entre autores nacionais e internacionais, que também aparecem como coautores nos estudos. É o caso de W. Glänzel, J. Leta e B. Thijs. Outras relações de coautoria entre autores nacionais e internacionais concretizam-se entre Narin e Velho e entre as duplas Sharan e Saxena com Gerolin e Mari. 


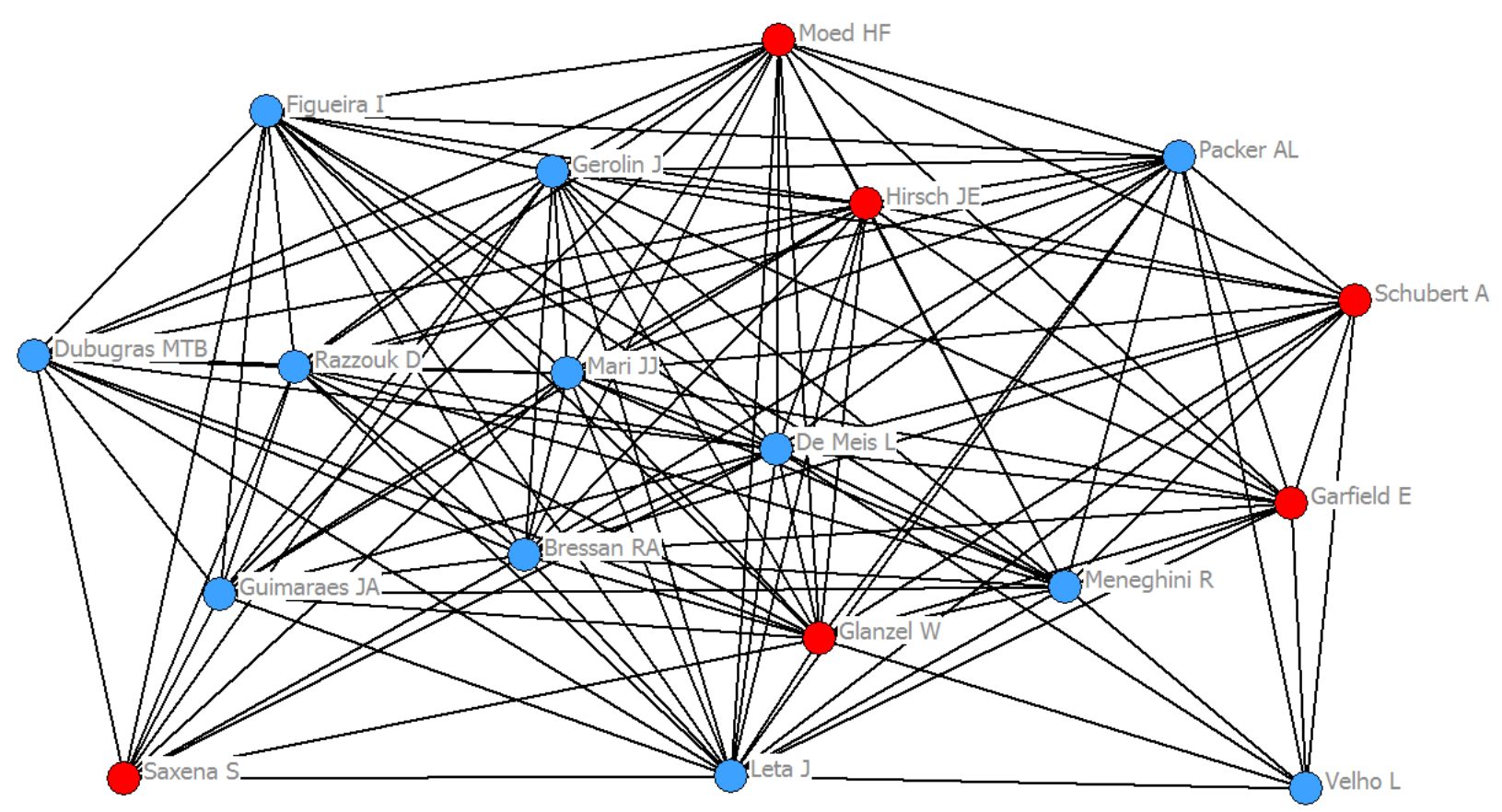

Legenda: vermelho: autores internacionais; azul: autores nacionais.

Figura 4 - Rede de cocitação entre os autores mais citados pelos artigos do corpus

Fonte: elaboração das autoras.

Glänzel é cocitado mais intensamente (pelo menos 10 cocitações) com Meneghini e Schubert. Já Garfield é mais cocitado (pelo menos 5 cocitações) com Hirsch, Moed, Packer, Meneghini e também com Glänzel.

Por fim, a Tabela 8 apresenta cinco agrupamentos dos autores mais produtivos, reunidos por similaridade em relação às temáticas trabalhadas, aos grupos-alvo da bibliometria em que atuam os autores mais citados.

O primeiro grupo destaca-se pela expressiva quantidade de trabalhos, especialmente na categoria temática 'Análise de produção científica' e depois na 'Política científica', também se adequando aos grupos-alvo G2 e G3 simultaneamente. Isso mostra que as análises da produção científica se voltam às políticas específicas de cada subdomínio estudado. Além disso, os autores desse grupo contribuem, embora em menor intensidade, para o desenvolvimento do próprio domínio devido aos artigos que apresentam no G1 e no G2 simultaneamente.

O segundo grupo é formado por dois pesquisadores da psiquiatria e outro com titulação na estatística. Sua predominância de produção está na categoria temática “Análise de produção científica”, com menor incidência em 'Política científica' e em 'Indicadores e métodos de avaliação'. Além dessas aproximações temáticas, os estudos desses autores figuram, de modo predominante, em G2 e G3 e em G3, sem nenhuma ocorrência para os estudos que desenvolvem o próprio domínio, ou seja, o G1.

O terceiro grupo é representado apenas por autores da medicina, com a maior parte de sua produção categorizada em 'Política científica' e em G2 e G3. Há pequena quantidade de artigos que se adequam a G1, G2 e G3. Esse grupo também contribui, mesmo que de modo pouco expressivo, para a definição do interdomínio.

O quarto e menor grupo, formado por dois autores da medicina na especialidade de cirurgia experimental, tem seus estudos adequados prioritariamente à categoria temática "Indicadores e métodos de avaliação" e em seguida em “Análise de produção científica”. Destaca-se que essa produção 
faz parte dos grupos-alvo G1 e G2; G1 e G3; G2 e G3; e também do G2. Portanto, esses pesquisadores, embora produzam pesquisas aplicadas ao seu domínio de especialidade, são relevantes no G1. Esse fato concorda com a maior proximidade dos autores com a temática "Indicadores e métodos de avaliação", significando que buscam desenvolver os EMI para melhor aplicá-los em seus respectivos campos de atuação.

Por último, o quinto e maior grupo constitui-se de autores de diferentes áreas, com produção científica permeando grupos temáticos diversificados, em especial 'Redes de colaboração e cooperação científica', 'Análise de produção científica' e 'Política científica' Publicam artigos com diferentes finalidades da pesquisa bibliométrica, segundo os grupos-alvo de Glänzel, mas, primordialmente em G2 e G3; G1 e G3; além de outras combinações, como G1, G2 e G3; e com menor expressividade em G2, e em G1 e G2. Em síntese, esse grupo de autores é o que caracteriza de forma mais consistente o interdomínio, com publicações que visam desenvolver metodologias e perspectivas analíticas para a produção, gestão e avaliação produção científica.

\section{Tabela 8 - Agrupamento dos autores, segundo temáticas trabalhadas, grupos-alvo da bibliometria e autores citados}

(continua)

\begin{tabular}{|c|c|c|c|c|c|c|c|c|c|c|c|c|c|c|c|c|c|c|c|c|c|c|c|c|c|c|c|c|c|c|c|}
\hline \multirow[b]{2}{*}{$\mathrm{AU}$} & \multicolumn{9}{|c|}{ Temáticas tratadas } & \multicolumn{7}{|c|}{$\begin{array}{l}\text { Grupos-alvo da bibliometria } \\
\text { (Glänzel, 2003) }\end{array}$} & \multicolumn{15}{|c|}{ Autores citados } \\
\hline & $A$ & B & C & $\mathrm{D}$ & $E$ & $\mathrm{~F}$ & G & $\mathrm{H}$ & I & J & K & L & M & $\mathrm{N}$ & $\mathrm{O}$ & $\mathrm{P}$ & Q & $\mathrm{R}$ & $S$ & $\mathrm{~T}$ & $U$ & V & W & $x$ & $\mathrm{Y}$ & Z & AA & $A B$ & $A C$ & $A D$ & $\mathrm{AE}$ \\
\hline Oliveira MCLA & 0 & 6 & 0 & 2 & 0 & 0 & 0 & 0 & 0 & 0 & 1 & 0 & 0 & 1 & 5 & 0 & 2 & 3 & 1 & 1 & 3 & 2 & 1 & 1 & 0 & 4 & 2 & 4 & 0 & 3 & 4 \\
\hline Quirino IG & 0 & 5 & 0 & 2 & 0 & 0 & 0 & 0 & 0 & 0 & 1 & 0 & 0 & 1 & 5 & 0 & 2 & 3 & 1 & 1 & 3 & 2 & 1 & 1 & 0 & 4 & 2 & 4 & 0 & 3 & 4 \\
\hline Martelli DRB & 0 & 6 & 0 & 2 & 0 & 0 & 0 & 0 & 0 & 0 & 1 & 0 & 0 & 1 & 6 & 0 & 2 & 3 & 1 & 1 & 3 & 2 & 1 & 1 & 0 & 4 & 3 & 4 & 0 & 3 & 4 \\
\hline $\begin{array}{l}\text { Martelli Junior } \\
\mathrm{H}\end{array}$ & 0 & 6 & 0 & 2 & 0 & 0 & 0 & 0 & 0 & 0 & 0 & 0 & 0 & 1 & 4 & 0 & 2 & 3 & 1 & 1 & 3 & 2 & 1 & 1 & 0 & 4 & 3 & 4 & 0 & 3 & 4 \\
\hline Lima LS & 0 & 5 & 0 & 1 & 0 & 0 & 0 & 0 & 0 & 0 & 0 & 0 & 0 & 0 & 4 & 0 & 2 & 3 & 1 & 1 & 2 & 2 & 1 & 1 & 0 & 3 & 2 & 3 & 0 & 2 & 2 \\
\hline Colosimo EA & 0 & 4 & 0 & 1 & 0 & 0 & 0 & 0 & 0 & 0 & 1 & 0 & 0 & 0 & 4 & 0 & 2 & 3 & 1 & 1 & 2 & 1 & 1 & 1 & 0 & 3 & 2 & 3 & 0 & 2 & 4 \\
\hline Oliveira EA & 0 & 7 & 2 & 1 & 0 & 0 & 0 & 0 & 0 & 0 & 1 & 0 & 0 & 0 & 3 & 0 & 1 & 2 & 1 & 1 & 2 & 1 & 1 & 1 & 0 & 2 & 1 & 2 & 0 & 1 & 4 \\
\hline Figueira IL & 0 & 7 & 1 & 1 & 0 & 0 & 0 & 0 & 0 & 0 & 0 & 1 & 0 & 4 & 3 & 0 & 2 & 3 & 2 & 4 & 5 & 2 & 1 & 5 & 1 & 3 & 2 & 2 & 0 & 2 & 1 \\
\hline $\begin{array}{l}\text { Mendlowicz } \\
\text { MV }\end{array}$ & 0 & 6 & 1 & 3 & 0 & 0 & 0 & 0 & 0 & 0 & 0 & 1 & 0 & 6 & 3 & 0 & 2 & 2 & 1 & 3 & 4 & 2 & 1 & 4 & 1 & 3 & 2 & 2 & 0 & 2 & 1 \\
\hline Coutinho ESF & 0 & 6 & 0 & 0 & 0 & 0 & 0 & 0 & 0 & 0 & 0 & 1 & 0 & 3 & 3 & 0 & 1 & 1 & 0 & 1 & 3 & 1 & 0 & 4 & 0 & 1 & 1 & 1 & 0 & 1 & 0 \\
\hline Mari JJ & 0 & 5 & 0 & 7 & 3 & 1 & 0 & 0 & 1 & 0 & 0 & 0 & 1 & 2 & 13 & 0 & 2 & 7 & 0 & 7 & 14 & 11 & 0 & 5 & 0 & 10 & 3 & 9 & 0 & 9 & 0 \\
\hline Razzouk D & 0 & 1 & 0 & 7 & 0 & 1 & 0 & 0 & 1 & 0 & 0 & 0 & 0 & 1 & 9 & 0 & 1 & 3 & 0 & 2 & 7 & 5 & 0 & 1 & 0 & 5 & 1 & 4 & 0 & 4 & 0 \\
\hline Gerolin J & 0 & 1 & 0 & 7 & 0 & 0 & 0 & 0 & 1 & 0 & 0 & 0 & 1 & 0 & 8 & 0 & 0 & 5 & 0 & 6 & 7 & 6 & 0 & 4 & 0 & 5 & 2 & 3 & 0 & 3 & 0 \\
\hline Bressan RA & 0 & 4 & 0 & 0 & 1 & 0 & 0 & 0 & 1 & 0 & 0 & 0 & 0 & 1 & 4 & 0 & 1 & 3 & 0 & 4 & 4 & 5 & 0 & 3 & 0 & 3 & 1 & 2 & 0 & 2 & 0 \\
\hline
\end{tabular}




\begin{tabular}{|c|c|c|c|c|c|c|c|c|c|c|c|c|c|c|c|c|c|c|c|c|c|c|c|c|c|c|c|c|c|c|c|}
\hline \multicolumn{10}{|c|}{ Temáticas tratadas } & \multicolumn{7}{|c|}{$\begin{array}{l}\text { Grupos-alvo da bibliometria } \\
\text { (Glänzel, 2003) }\end{array}$} & \multicolumn{15}{|c|}{ Autores citados } \\
\hline Teixeira RKC & 0 & 3 & 3 & 0 & 0 & 0 & 0 & 0 & 0 & 0 & 2 & 1 & 0 & 2 & 1 & 0 & 0 & 0 & 0 & 0 & 0 & 0 & 0 & 0 & 0 & 0 & 4 & 0 & 0 & 0 & 0 \\
\hline Gouveia FC & 4 & 1 & 0 & 0 & 0 & 0 & 0 & 0 & 0 & 0 & 2 & 1 & 0 & 2 & 0 & 0 & 0 & 2 & 0 & 0 & 0 & 0 & 0 & 0 & 0 & 0 & 0 & 0 & 0 & 0 & 0 \\
\hline Pereira JCR & 0 & 4 & 2 & 2 & 0 & 0 & 0 & 2 & 1 & 0 & 0 & 2 & 2 & 2 & 5 & 0 & 3 & 3 & 4 & 2 & 0 & 0 & 1 & 1 & 0 & 0 & 1 & 0 & 0 & 0 & 1 \\
\hline Wainer J & 0 & 4 & 2 & 2 & 0 & 0 & 0 & 0 & 0 & 0 & 0 & 3 & 1 & 1 & 2 & 0 & 3 & 2 & 0 & 1 & 0 & 0 & 0 & 2 & 1 & 0 & 0 & 0 & 0 & 0 & 1 \\
\hline Meneghini R & 0 & 1 & 2 & 5 & 0 & 0 & 0 & 0 & 0 & 0 & 0 & 4 & 2 & 0 & 7 & 0 & 3 & 2 & 7 & 0 & 0 & 0 & 5 & 1 & 1 & 0 & 0 & 0 & 1 & 0 & 1 \\
\hline Packer AL & 2 & 0 & 3 & 3 & 0 & 0 & 0 & 0 & 0 & 0 & 0 & 6 & 1 & 1 & 0 & 0 & 2 & 1 & 6 & 0 & 0 & 0 & 6 & 0 & 1 & 0 & 0 & 0 & 1 & 0 & 0 \\
\hline $\begin{array}{l}\text { Herculano } \\
\text { RDA }\end{array}$ & 0 & 1 & 1 & 2 & 0 & 0 & 0 & 0 & 0 & 0 & 0 & 0 & 0 & 0 & 1 & 0 & 4 & 0 & 4 & 1 & 0 & 0 & 3 & 0 & 3 & 0 & 0 & 0 & 0 & 0 & 4 \\
\hline Velho L & 4 & 0 & 0 & 5 & 0 & 1 & 2 & 2 & 0 & 1 & 0 & 6 & 1 & 1 & 3 & 5 & 3 & 2 & 2 & 1 & 0 & 0 & 0 & 0 & 3 & 0 & 0 & 0 & 12 & 0 & 0 \\
\hline
\end{tabular}

Legenda: A = Red Colab Cient $\mid \mathbf{B}=$ Anal Prod Científica $\mid \mathbf{C}=$ Indic/Met Aval Cienc $\mid \mathbf{D}=$ Pol Cient $\mid \mathbf{E}=$ Map Cienc Brasil $\mid \mathbf{F}=$ Asp Soc Prod Cienc e Tec $\mid \mathbf{G}=$ Capac Pesq Inov Tecnol

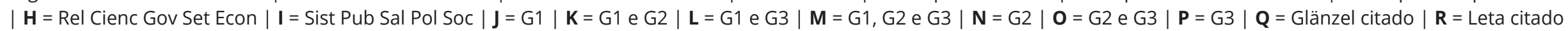
| $\mathbf{S}=$ Meneghini citado $\mid \mathbf{T}=$ Meis citado $\mid \mathbf{U}=$ Mari citado $\mid \mathbf{V}=$ Bressan citado $\mid \mathbf{W}=$ Packer citado $\mid \mathbf{X}=$ Figueira citado $\mid \mathbf{Y}=$ Garfield citado $\mid \mathbf{Z}=$ Gerolin citado $\mid \mathbf{A A}=$ Guimarães citado $\mid \mathbf{A B}=$ Razzouk citado $\mid \mathbf{A C}=$ Velho citado $\mid \mathbf{A D}=$ Dubugras citado $\mid \mathbf{A E}=$ Hirsch citado.

Fonte: elaboração das autoras.

\section{CONSIDERAÇÕES FINAIS}

Conclui-se que as relações do interdomínio se destacam em grupos específicos de periódicos e autores que o caracterizam. O núcleo de periódicos disseminadores dessa produção está centrado na medicina, produzindo, assim, um corpo de conhecimento metateórico em que os EMI atuam como método para a compreensão do comportamento e da evolução da medicina. Ainda, reconhece-se a gênese histórica dos EMI na CI por meio desta análise de produção científica.

Constata-se a expressiva presença de citação a periódicos brasileiros no corpus analisado, sendo oito deles nacionais, entre os 25 mais citados. A revista internacional Scientometrics, como a mais incidente, com $25 \%$ do corpus analisado, reflete a institucionalização social dos EMI, como disciplina científica, e caracteriza um fórum de articulação de diferentes domínios, embora com um perfil específico, em suas vertentes e estruturas de comunicação científica. Destaca-se a revista Perspectivas em Ciência da Informação entre as sete citantes mais produtivas. Entre as citadas, merece destaque a revista Ciência da Informação, a mais antiga do Brasil na área. 
Em relação à autoria, 77\% dos autores apresentam graduação nas ciências da saúde e ciências biológicas, sendo que, desses, 40\% são médicos psiquiatras ou afiliados a departamentos de saúde mental. Observa-se, também, que 79\% dos autores mais citados são aqueles mais produtivos, o que sugere haver uma quantidade expressiva de autocitações usadas como fundamento desses estudos. Todavia, as autocitações justificam-se, principalmente, porque a comunidade que trabalha com os estudos métricos e que subsidia a aplicação e a construção do conhecimento em EMI na medicina é pequena.

O maior grupo que trabalha em coautoria representa duas instituições de pesquisa do estado de Minas Gerais, a saber: UFMG e Unimontes. Nesse grupo, 57\% dos autores são médicos e apresentam ativa participação no domínio de EMI. Parcerias entre pesquisadores de instituições de pesquisa do Rio de Janeiro são destacadas no segundo maior grupo de coautoria. São elas a UFRJ, Fiocruz e a UFF, em que $67 \%$ dos autores são médicos.

A Unifesp é a instituição da qual procede o terceiro maior grupo de trabalho em coautoria, com destaque para a área de psiquiatria e saúde mental. Embora seja menor que os afiliados às instituições dos estados do Rio de Janeiro e de Minas Gerais, esse grupo de coautores destaca-se pela maior quantidade de pesquisadores como um todo na rede e pela homogeneidade de domínios de atuação e de formação.

Esses resultados indicam que, no Brasil, o interdomínio estudado se estrutura por meio de um grupo coeso e centrado em instituições específicas na região Sudeste do país. Arrisca-se sugerir que alguns dos autores em destaque na rede de colaboração seriam pioneiros desse interdomínio no Brasil, visto que são referendados no domínio de estudos métricos consignado à Ciência da Informação.

Observa-se, ainda, como os agrupamentos de autores mais atuantes na constituição do interdomínio como um campo de pesquisa são aqueles que apresentam expressiva quantidade de artigos categorizados nos três grupos-alvo de bibliometria postulados por Glänzel (2003) e que, simultaneamente, apresentam como objetos de estudo a análise de produção científica e as políticas científicas. Destaca-se, assim, o interdomínio em sua complexa trama de relações, cuja organicidade delas depende. Os artigos do corpus diferem em finalidades e combinação de autores e publicações, ensejando possibilidades analíticas, a partir de outros recortes, olhares, delineamentos e de outras formas interpretativas.

Os aspectos a serem superados para a realização de EMI em ambos os campos, medicina e Ciência da Informação, convergem em suas características de produção e evidenciam a necessidade de trabalho conjunto com profissionais da ciência da computação e da estatística. Com efeito, pode-se sugerir um fortalecimento do ensino dessas disciplinas nos cursos de formação de pesquisadores em CI e medicina, especialmente no que tange aos conhecimentos mais utilizados, oriundos desses domínios para o trabalho com os EMI.

Ainda vale dizer que as políticas científicas de avaliação de programas de pós-graduação restringem as possibilidades de trabalhos com interdomínios e que o reconhecimento de interdomínios por meio dos EMI ajuda a fortalecê-los como campo, abrindo possibilidades para que a CI trabalhe em prol do desenvolvimento e aperfeiçoamento de ferramentas e de indicadores que melhor retratem o campo de produção científica.

\section{REFERÊNCIAS}

ARAÚJO, Carlos Alberto Ávila. Arquivologia, biblioteconomia, museologia e Ciência da Informação: o diálogo possível. Brasília, DF: Briquet de Lemos; São Paulo: ABRAINFO, 2014.

BUFREM, Leilah Santiago; FREITAS, Juliana Lazzarotto; GABRIEL JR., Rene Faustino. Produção científica sobre estudos métricos: configurações temáticas e de autoria (1972-2013). In: ENCONTRO NACIONAL DE PESQUISA EM CIÊNCIA DA INFORMAÇÃO (ENANCIB): Além das nuvens: expandindo as fronteiras da Ciência da Informação, 14., 2014, Belo Horizonte. Anais [...]. Belo Horizonte: ANCIB, 2014. p. 3409-3421. 
BUFREM, Leilah Santiago; FREITAS, Juliana Lazzarotto. Interdomínios na literatura periódica científica da Ciência da Informação. DataGramaZero - Revista de Informação, Rio de Janeiro, v. 16, n. 4, out. 2015. Disponível em: https://www.brapci.inf.br/index.php/article/download/50746. Acesso em: 24 set. 2021.

DAHLBERG, Ingetraut. Domain interaction: theory and practice. In: ALBRECHTSON, Hanne; OERNAGER, Susanne (ed.). Knowledge organization and qualitative management: proceedings of the Third International ISKO Conference 20-24 June 1994 Copenhagen, Denmark. Frankfurt: Indeeks Verlag, 1994. p. 60-75.

FREITAS, Juliana Lazzarotto. Dimensões da pesquisa brasileira no interdomínio dos Estudos Métricos da Informação em medicina. 2017. 201 f. Tese (Doutorado em Ciência da Informação) - Faculdade de Filosofia e Ciências, Universidade Estadual Paulista Júlio de Mesquita Filho, Marília, 2017.

FREITAS, Juliana Lazzarotto; BUFREM, Leilah Santiago; GRÁCIO, Maria Cláudia Cabrini. O interdomínio dos Estudos Métricos da Informação em medicina: aproximação entre discurso e prática de seus pesquisadores. Encontros Bibli: Revista Eletrônica de Biblioteconomia e Ciência da Informação, Florianópolis, v. 24, n. 56, p. 1-22, 2019. DOI: https://doi.org/10.5007/1518-2924.2019.e65348. Disponível em: https://periodicos.ufsc. br/index.php/eb/article/view/1518-2924.2019.e65348. Acesso em: 24 set. 2021.

GLÄNZEL, Wolfgang. Bibliometrics as a research field: a course on theory and application of bibliometric indicators. [S. I.: s. n.], 2003. Disponível em: https://www.cin.ufpe.br/ ajhol/futuro/references/01\%23 Bibliometrics Module KUL BIBLIOMETRICS\%20AS\%20A\%20RESEARCH\%20FIELD.pdf. Acesso em: 9 fev. 2021.

GRÁCIO, Maria Cláudia Cabrini; OLIVEIRA, Ely Francina Tannuri. A inserção e o impacto internacional da pesquisa brasileira em "estudos métricos": uma análise na base Scopus. Tendências da Pesquisa Brasileira em Ciência da Informação, [s. I.], v. 5, n. 1, p. 1-19, 2012. Disponível em: https://repositorio.unesp.br/ handle/11449/114791. Acesso em: 24 set. 2021.

HJØRLAND, Birger. Domain Analysis. Knowledge Organization, Edmonton, v. 44, n. 6, nov. 2017, p. 436464. (Reviews of Concepts in Knowledge Organization).

HJØRLAND, Birger; ALBRECHTSEN, Hanna. Toward a new horizon in information science: domain-analysis. Journal of the American Society for Information Science and Technology, [s. I.], v. 46, n. 6, p. 400425, 1995. DOI: https://doi.org/10.1002/(SICI)1097-4571(199507)46:6\%3C400::AID-ASI2\%3E3.0.CO:2-Y. Disponível em: https://asistdl.onlinelibrary.wiley.com/doi/10.1002/(SICl)1097-4571(199507)46:6\%3C400::AIDASI2\%3E3.0.CO;2-Y. Acesso em: 27 set. 2021.

LLOYD, Christopher. As estruturas da história. Rio de Janeiro: Zahar, 1995.

MATTOS, Ana Maria; JOB, Ivone. A produção científica brasileira no periódico Scientometrics de 1978 até 2006. Encontros Bibli: Revista Eletrônica de Biblioteconomia e Ciência da Informação, Florianópolis, v. 13, n. 26, p. 47-61, 2008. DOI: https://doi.org/10.5007/1518-2924.2008v13n26p47. Disponível em: https:// periodicos.ufsc.br/index.php/eb/article/view/1518-2924.2008v13n26p47. Acesso em: 24 set. 2021.

PACKER, Abel Laerte et al. SciELO: uma metodologia para publicação eletrônica. Revista Ciência da Informação, Brasília, DF, v. 27, n. 2, maio/ago. 1998, p. 109-121. DOI: https://doi.org/10.1590/S010019651998000200001. Disponível em: https://www.scielo.br/j/ci/a/XhRCDr87m5VTswK5WtNdYzL/ abstract/?lang=pt. Acesso em: 27 set. 2021.

PACKER, Abel Laerte et al. (Org). SciELO - 15 anos de acesso aberto: um estudo analítico sobre acesso aberto e comunicação científica. Paris: Unesco, 2014. DOI: https://doi.org/10.7476/9789237012376. Disponível em: http://www.scielo15.org/livro-scielo-15/. Acesso em: 24 set. 2021.

REVISTA CUBANA DE INFORMACIÓN EN CIENCIAS DE LA SALUD. Políticas de la editorial. Havana: Centro Nacional de Información de Ciencias Médicas, [2016]. Disponível em: http://www.acimed.sld.cu/index. php/acimed/about/editorialPolicies\#focusAndScope. Acesso em: 01 mar. 2021.

TEIXEIRA, Renan Kleber Costa et al. Citing of national articles: the (de)valuation of Brazilian journals. Revista do Colégio Brasileiro de Cirurgiões, Rio de Janeiro, v. 39, n. 5, 2012, p. 421-424. DOI: https://doi. org/10.1590/S0100-69912012000500015. Disponível em: https://www.scielo.br/j/rcbc/a/SVCWWnx9r5kmCNTn dpxYpyf/?lang=pt. Acesso em: 27 set. 2021. 
Reciis - Revista Eletrônica de Comunicação, Informação \& Inovação em Saúde, Rio de Janeiro, v. 15, n. 4, p. 890-913, out./dez. 2021 [www.reciis.icict.fiocruz.br] e-ISSN 1981-6278

TEIXEIRA, Renan Kleber Costa et al. Citations of Brazilian physical therapy journals in national publications. Brazilian Journal of Physical Therapy, Sâo Carlos, v. 18, n. 1, 2014, p. 88-92. DOI: 10.1590/s141335552012005000138. Disponível em: https://www.scielo.br/j/rbfis/a/Jddcm6QYmVgb4Rpm5FFVbSJ/?lang=en. Acesso em: 27 set. 2021.

TEIXEIRA, Renan Kleber Costa et al. Does impact factor influence the ethics of the instructions provided to journal authors? Revista da Associação Médica Brasileira, São Paulo, v. 59, n. 3, 2013, p. 280-284. Disponível em: https://www.sciencedirect.com/science/article/pii/S0104423013000511?via\%3Dihub. DOI: https://doi.org/10.1016/j.ramb.2012.12.003. Acesso em: 27 set. 2021. 